\title{
Assessment of Housing Needs in the Core Area of Akure, Nigeria
}

\section{Gbenga Enisan}

Department of Urban and Regional Planning, Federal University of Technology, Akure, Nigeria

Email address:

ofenisan@futa.edu.ng, enisangbenga@yahoo.com

\section{To cite this article:}

Gbenga Enisan. Assessment of Housing Needs in the Core Area of Akure, Nigeria. International Journal of Environmental Monitoring and Analysis. Vol. 7, No. 4, 2019, pp. 75-84. doi: 10.11648/j.ijema.20190704.11

Received: January 10, 2019; Accepted: March 12, 2019; Published: September 21, 2019

\begin{abstract}
This research examined housing needs in the core area of Akure, Nigeria. This was carried out by identifying the existing housing stock, housing condition and the extent of housing needs in the study area. Six residential neighborhoods were selected from the core area of the city due to their homogeneity characteristics. The study made used of the existing demographic and land use characteristics, primary and secondary data were used for the data collection. A total number of 198 buildings were selected and sampled in the area. Literature was also consulted for proper understanding of the subject matter. The study revealed that, houses in the study area had poor environmental outlook. On housing condition, 50\% of the dwellings assessed were either sub-standard or unfit for human habitation. More than $50 \%$ of the residential buildings had one or more major defects. Some of the houses were overcrowded and subjected to tenant's abuse by internal conversion to increase the occupancy rate. The research recommends the need for affordable housing strategy, governmental and institutional intervention to cater for general inadequacies of infrastructures, such as roads, drains, waste disposal and recreational facilities. Stakeholders should collaborate towards enforceable standards for redevelopment and upgrading that could guarantee sustainable development.
\end{abstract}

Keywords: Housing Needs, Residential, Core Area, Development

\section{Introduction}

Urbanization is a phenomenon which is observed all over the world whether a nation is developed or developing. The main cause of urbanization is being attributed to migration and increase in population which has various impacts on the city's structure [27]. One of the most significant impacts is seen on the housing sector as residential land use is predominant over other land uses. Therefore, urbanization trends, causes of urbanization and its impacts on housing sector is dominant and need more attention while preparing development plans and regional plans. Urban populations have increased rapidly in the past decades, this often outstripping available housing [3]. A century ago, two of every 10 people lived in urban areas; now, for the first time in human history, more than half now live in cities. India alone has 35 urban areas with more than a million people, and at least a dozen cities worldwide are home to more than 10 million populations [27]. Cities are places of both great opportunity and inequality. Close to 1 billion dwell in urban slums, and everywhere children are disproportionately at risk [28]. In the United State, for example, the fastest-growing urban centers account for three-fourths of the recent growth among children and youth. Habitat responds to the needs of our urbanizing world, helping to create strong, sustainable cities with decent and affordable housing for everyone.

Housing need in Nigeria increases by the day, whereas the vast majority of the population lacks the wherewithal to make effective demand on housing [20]. The private sector, which is the major supplier of housing in Nigeria, faces a number of problems inhibiting it from meeting the ever increasing needs. The public sector has fared badly in housing provision. A major reason for the debacle in past public sector programs in housing are traceable to inadequate knowledge of the nature, scope and dimension of the housing problems in both the rural and urban areas of the country, and to the myopic and narrow concept of the housing needs of the Nigerian populace. The absence of research on housing is a lag in the housing delivery system in developing countries, especially Nigeria [2]. 
Conditions of urban housing in Nigeria are very deplorable $[18,16,4,20,21]$. This is in spite of public sector intervention in housing in Nigeria. Studies affirmed that, $75 \%$ of the dwelling units in urban centers in Nigeria were substandard and sited in slums. The inadequacy of the quality of most of urban housing manifests mainly in the poor physical state of the buildings. They are often unsafe and insecure and do not provide adequate shelter from the elements of weather. Walls of the buildings are built mainly with poor sand Crete blocks, and concrete used for construction often contain excessive quantities of dust and clayey matter. This is inimical to the production of good quality concrete [20]. In most cases, the environment in which the buildings are located is squalid, and this generally leads to slum.

The rate of urbanization in Akure outpaces the rate of economic development. It is currently experiencing a high pace of urbanization compared to other emerging cities in Nigeria [10]. However, some neighborhoods of the city can best be described as slum characterized by congested district, deteriorating, unsanitary housing environments and noticeably poverty area [17]. Despite the enormous amount of money proposed for urban investment in the National Development Plan, very limited investment was made in her infrastructure. An increasing shortage of urban services and infrastructure characterized Akure town, and these were only accessible to a diminishing share of the population. This necessitated the need to carry out an assessment of housing needs in Nigeria urban centers using the core area of Akure as a case study.

\section{Review of Housing Needs in Nigeria Urban Centers}

The cost and quality of one's housing are among the most important factors influencing quality of life in America. Housing represents the largest expense as well as the largest investment for most households [7]. When housing is unaffordable, overcrowded, or unhealthy, it can affect the financial, educational, and emotional well-being of individuals and families [5, 9, 25]. When poor households and low-quality housing is concentrated in a single area, the negative ramifications of individual housing challenges substantially increase $[12,13,26]$. Furthermore, such concentration of poverty often correlates to a concentration of racial and ethnic minorities $[6,16]$. The resulting racial and economic segregation limits residents' access to goods and services, including poor public education and decreased access to employment centers [13]. Developing affordable housing in non-poor areas promotes both racial and social integration, promoting access to opportunity and mitigating many of these negative outcomes.

Meeting the housing needs of urban dwellers especially in the core area is a challenging issue in developing countries. The needs, both in quality and quantity have always been assessed based on what experts in housing issues think. For instance, housing quality based on used socio-cultural parameters had been assessed [16]. Housing Quality Survey (HQS) and Environmental Survey (ES) was employed as measures of the quality of the dwelling units and neighborhood respectively [8]. Many works have been done in assessing the physical characteristics of housing in the core areas, but no attempt has been made to examine core area housing based on environment behavior issues which define how the dwellers themselves feel about their housing.

\subsection{Quantity of Existing Housing Stock in Nigeria}

Studies have confirmed the profound inadequacy in the housing circumstances of Nigerians, in particular the lowincome population $[17,19,23]$. The housing circumstances of low-income earners, who incidentally constitute the vast majority of the population in Nigeria, have not shown any significant improvement over the years.

Between 1975 and 1980, there were plans of deliver 202,000 housing units to the public but only 28,500 units, representing $14.1 \%$ was achieved. Also, out of 200,000 housing units planned to be delivered between 1981 and 1985 , only 47,200 (23.6\%) was constructed [28]. Under the National Housing Fund (NHF) programme initiated in 1994, to produce 121,000 housing units, it was believed that less than $5 \%$ was achieved. In spite of a series of government policies towards housing delivery, there exists a gap between housing supply and demand.

Table 1. Estimated Housing needs Nigeria (1991 - 2001).

\begin{tabular}{llll}
\hline & Urban areas & Rural areas & Total \\
\hline Housing stock 1991 ('000 units) & 3,373 & 11,848 & 15,221 \\
Estimate no of households 2001 & 7,289 & 15,295 & 22,584 \\
Required output 1991 - 2001 ('000) & 3,916 & 3,447 & 7,363 \\
Required annual output, 1991 - 2000 & 391.6 & 344.7 & 736.3 \\
\hline
\end{tabular}

[28]

Table 2. Estimated Housing Stock, by dwelling types in Nigeria (1991).

\begin{tabular}{|c|c|c|c|c|c|c|}
\hline & Urban & Urban & Rural & Rural & Total & Total \\
\hline & $\%$ & unit & $\%$ & unit & $\%$ & Unit \\
\hline Maisonnette & 2 & 67 & 0 & 12 & 1 & 79 \\
\hline Duplex & 3 & 101 & 0 & - & 1 & 101 \\
\hline Detached Bungalow & 10 & 337 & 20 & 2,289 & 17 & 2627 \\
\hline
\end{tabular}




\begin{tabular}{lllllll}
\hline & Urban & Urban & Rural & Rural & Total & Total \\
\cline { 2 - 7 } & $\mathbf{\%}$ & unit & \% & unit & \% & Unit \\
\hline Semi-detached & 12 & 67 & 1 & 60 & 1 & 127 \\
Flats & 15 & 506 & 0 & - & 3 & 506 \\
Rooms & 65 & 2,194 & 77 & 9,200 & 74 & 11393 \\
Others & 3 & 101 & 2 & 287 & 3 & 388 \\
Total & 100 & 3,375 & 100 & 11,848 & 100 & 15221 \\
\hline
\end{tabular}

[28]

Since housing occupies a central position in the sustainable urbanization agenda in Nigeria and other developing nations; and also since African traditional family housing unit constitutes a significant component of the urban housing stock, there is the need to ensure its adequacy in other to facilitate a better quality life as well as maintain stable urban communities.

\subsection{Review of Core Area Housing}

The core areas of most world cities were the oldest parts as well as the economic nerve centers of the towns [9]. They are also referred to as city centers, down town or the Central Business District (CBD). In West-African cities, the case is different as economic activities are located some distance away from the core areas because the core areas were mainly residential. The core areas of these cities which used to be the location of principal markets, has ceased to be because of European influence. The commercial region was some distance away from the core which withdrew the attention of the colonialists from issues related to the development of these areas. Consequently, the core areas of indigenous West Africa towns have become derelict and plans to renew are almost unrealized [10]. Other causes of the problems of the core area can be traced to a number of factors which include:

a) Socio-cultural: To a Yoruba, living closely to extended family members and friends is important. It is believed that groups of relatives and friends shares their happiness and sorrows and who are socially knit by loyalty to the family group. To them the needs of their kinsmen are their first responsibility (Aldous, 1962). Therefore, their desire to live closely to members of the extended family either for economic, social and security reason brought about congestion in the core areas.

b) Multiple Ownership (Family House Concept): The family house concept is another contributing factor to the deploring state of the core area. Family house was described as "Ori'run", meaning "origin or source of the ancestors", and also "Agbo-Ile", meaning "Flock of houses" [10]. It is therefore unusual for a single member of the family to talk of rehabilitation without the consent of others. This led to the continuous deterioration of the core area housing.

c) Economic factors: Another factor contributing to housing inadequacy in the core area is economic problem [17]. The high rate of poverty in the developing countries has made it impracticable to get funds for the redevelopment of core areas.
These problems of core areas reinforce the need for redevelopment actions to be taken which could only be responsive if the dwellers themselves are allowed to define their housing needs.

\subsection{The Concept of Housing Affordability}

The rationale for housing assistance is to improve housing affordability for those receiving the assistance [1]. Therefore, since the concept is an essential component of sustainable development, it is germane and central to the present discuss. "Affordable housing" is defined as that which costs no more than 30 percent of the income of the occupant household [14]. This is the generally accepted definition of housing affordability. She also described severe housing burdens as 50 percent or more of household income. Families who pay more than 30 percent of their income on housing are considered cost burdened and may have difficulty affording necessities such as food, clothing, transportation and medical care [12].

The Chartered Institute of Housing (1992) identified four key variables or items which will determine whether accommodation is affordable or not. These variables are: Rent levels which will have an impact on the ability of a tenant to afford accommodation, household income, the type of household (that is Family makeup, whether couple, single parent, elderly, etc.) and whether the household is eligible for housing benefits.

From the above, affordable housing may therefore be described as housing in which the occupant is not paying more than 30 percent of his or her income on. The 30 percent threshold has been criticized in the literature as deceptive, for low income families, spending 30 percent on housing costs leave very little for all other necessities, whereas for middleincome families, it is an appropriate expenditure level [1]. Rule of thumb is inconsistent with what people actually spend on housing [7]. Also, the important determinant of what consumers regard as affordable housing is the scope for trade- offs between different forms of expenditure and their relative attraction [14]. However, affordability "is virtually undefined concept and certainly cannot be neatly or simply understood in terms of a fixed percentage of income". Whereas, housing affordability is a behavioral concept and it changes with time. It is also individualized as the relationship between incomes and how much the household is ready to put into housing is not a direct one. Despite these problems, the 30 percent threshold is currently the most widely used and widely accepted indicator of housing affordability [14]. 


\subsection{The Concept of Habitability}

Housing quality is related to adequate housing as well as habitable housing. This is a function of the ratings of the individual tenant's level of satisfaction with his dwelling unit in relation to his neighborhood. That, assessing habitability would mean evaluating the level of satisfaction of a tenant, living in a particular community and managed under a type of institutional management.

A good housing should consider the location of dwelling places as they relates to the various places of interaction. The physical appearance and the social reputation of the neighborhood are significant aspect of a good housing. All housing need to achieve to be successful are to be socially and culturally valid; it should be sufficiently economical to ensure that the greatest number can afford it, it should ensure the maintenance of the health of the occupants and there should be a minimum of maintenance over the life of the building $[25,26]$.

The concept of "a habitable home" or "an ideal home" is related to the physical, architectural, and engineering component of the home, to; the social, behavioral, cultural, and personal characteristics of the inhabitants; the component of the environment of which the home is a part; and the nature of the institutional arrangement under which the house is managed [14]. Hence, housing quality, adequate shelter and habitable homes are relatively used to connote housing that satisfies the basic physiological needs of the tenant.

\subsection{The Neighborhood Concept}

The term neighborhood is often used to describe the subdivisions of urban or rural locations such as cities, villages, and towns. In its purest definition, a neighborhood is the vicinity in which people live. People live next to or near one another in sections of an area and form communities. Those sections have some particular physical or social characteristics that distinguish them from the rest of the settlements. The basic physical attributes of the space defined by the term neighborhood have been described in detail by [9]. Accordingly, the neighborhood is a comprehensive planning increment. The clustering of neighborhoods forms towns, villages, and cities.

The concept of neighborhood forms an integral part of the residential environment. While attempting to assess the dwelling occupants' satisfaction from the overall residential environment, it should be considered that different performance criteria apply to different physical components of the residential environment. Those components and the relevant performance criteria are evaluated with a user / user group and physical space interaction.

The concept of housing affordability will be adopted for this study research. This is as a result of its importance in securing some given standards of housing or different standards at a price or rent. This does not impose an unreasonable burden on household incomes and it is also assessing the quantitative housing needs of core area housing. It will also ensure that the normal power for the development of individual housing as well as housing purchase. This will in turn reduce the gap created by housing needs in Nigeria and Akure in particular. It will also provide the framework for the enhancement of mass ownership of housing which will increase the number of home ownership.

\section{Research Method}

Akure is one of the traditional Yoruba towns in Nigeria and has been in existence long before the advent of British colonial rule in Nigeria. Akure was an independent region, until 19th century when it was included in Benin Kingdom. Great Britain took over the control of the region in 1894. The city is located within Ondo State in the South Western part of Nigeria. The current medium-sized urban center became the provincial headquarter of Ondo province in 1939 and capital city of Ondo State and a Local Government headquarters in 1976. The city lies approximately on latitude $70^{\circ} 15^{\prime}$ north of the Equator and longitude $50^{\circ} 15^{\prime}$ east of the Greenwich Meridian [1].

The increased relative political influence of Akure as a state capital since 1976 has greatly promoted its rapid growth and increased socio-economic activities. The 1991 national population census, reported the population of Akure as 239,124 and its estimated population in 1996 was 269,207 as given by [15]. At present the city is estimated to have over 350,000 people. The city's morphology has changed over time to assume its present status with its attendant housing problems, as experienced in similar medium sized urban centers in Nigeria.

The study adopted a systematic random sampling technique. Sometimes, it is expedient for the researcher to assume that the items to be selected are randomly distributed or listed in the sampling frame and then has to choose $1 / k t h$, where $\mathrm{k}$ is the constant. The value of $\mathrm{k}$ is normally determined by the researcher and it is usually dependent upon the size of the sample that is to be selected by the sample frame. If $\mathrm{k}$ is too large, the researcher might run out of respondent before the research is completed.

At the first stage all the core areas in Akure was identified and at the second stage Six settlements were chosen randomly for this research, the settlements are Isolo, Ijomu, Ilemo, Eruoba, and Ijemikin. These settlements are chosen out of all the existing 22 settlements in the core area of Akure because they exhibit the same character with settlements along their corridor. These characters include; homogeneity, socio-economic profile, age of development, settlement pattern, living standard, among others. 

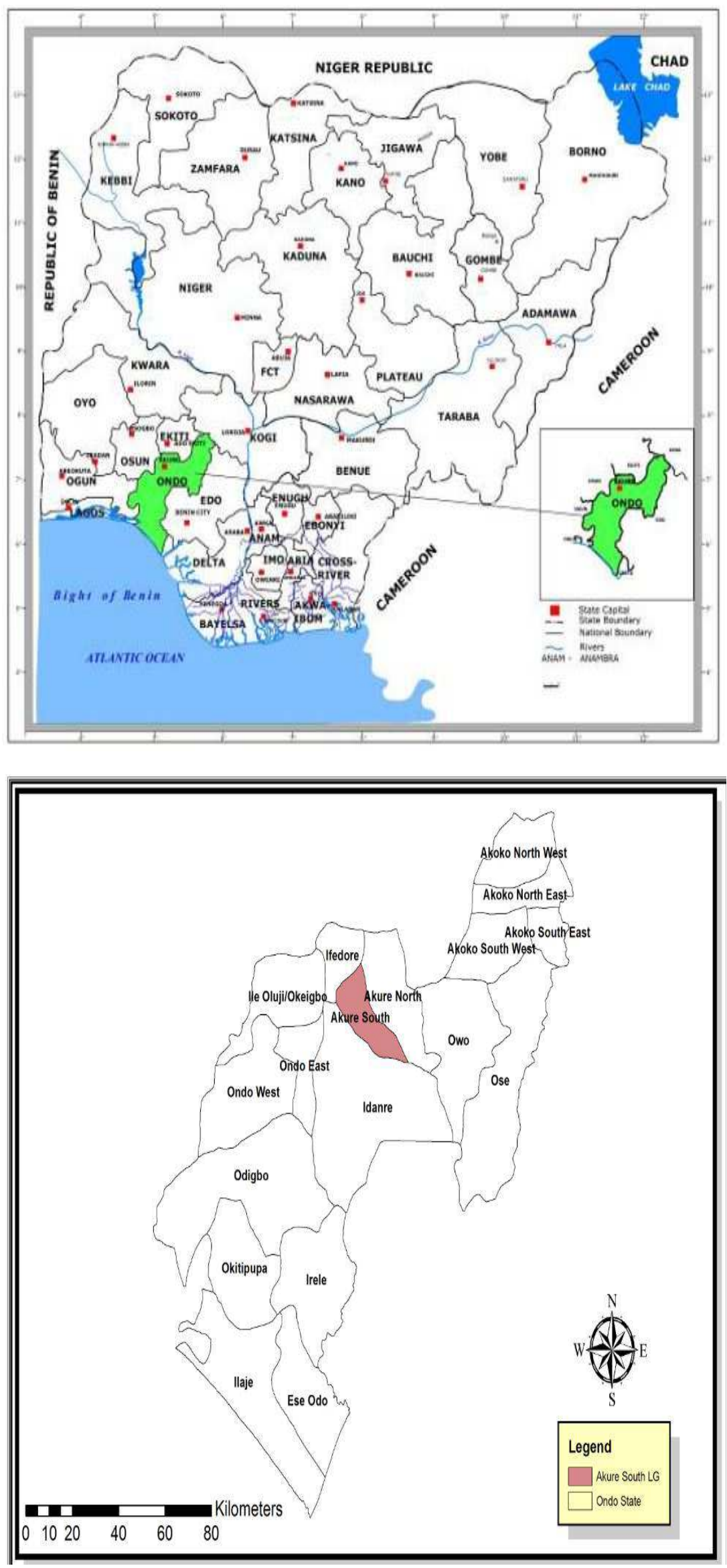

Figure 1. Akure in the context of Nigeria. 
Table 3. Selected settlements in the core area of Akure.

\begin{tabular}{lllll}
\hline S/N & Name of settlements/area & Number of existing buildings & Percentage chosen (\%) & Number of sample selected. \\
\hline 1 & Isolo & 287 & 10 & 29 \\
2 & Ijomu & 438 & 10 & 43 \\
3 & Ilemo & 199 & 10 & 20 \\
4 & Eruoba & 384 & 10 & 38 \\
5 & Ijemikin & 196 & 10 & 19 \\
6 & Eyinke & 490 & 10 & 49 \\
Total & & 1,987 & & 198 \\
\hline
\end{tabular}

At the third stage, the number of buildings was identified through Google map and digitizing using ArcGIS. All residential buildings were enumerated and buildings were randomly selected irrespective of whether the building is owner - occupied or non - owner occupied (rented) by choosing every $10^{\text {th }}$ building along the street after the first building has been drawn randomly. Thus, a total of 198 residential buildings were selected for sampling. 10\% sample size was considered adequate to capture the study area based on the homogeneity of the people living in the neighborhoods. These includes; nativity, tribe, language, their socio-economic nature, their income level, age of development (age of buildings), settlement pattern, among others. A smaller percent of 5\% was considered valid and reliable, $10 \%$ sample size was also used to obtain acceptable result for housing density mix in Akure [10, 20]. This research made use of simple survey method to collect information through primary source of data such as, field observation, questionnaire construction, oral interview and secondary sources of data. The data obtained for this research were analyzed and hypothesis was tested using MannWhitney U test.

\section{Findings}

The population for this research consists of the residential core area of Akure, which is the center of the town. 22 neighborhoods were identified in the core area during the survey (Figure 2) and they are mainly dominated by low income earners and is bounded by Oba Adesida Road to the North, Oke- Aro Road to the West and Hospital Road to the East.

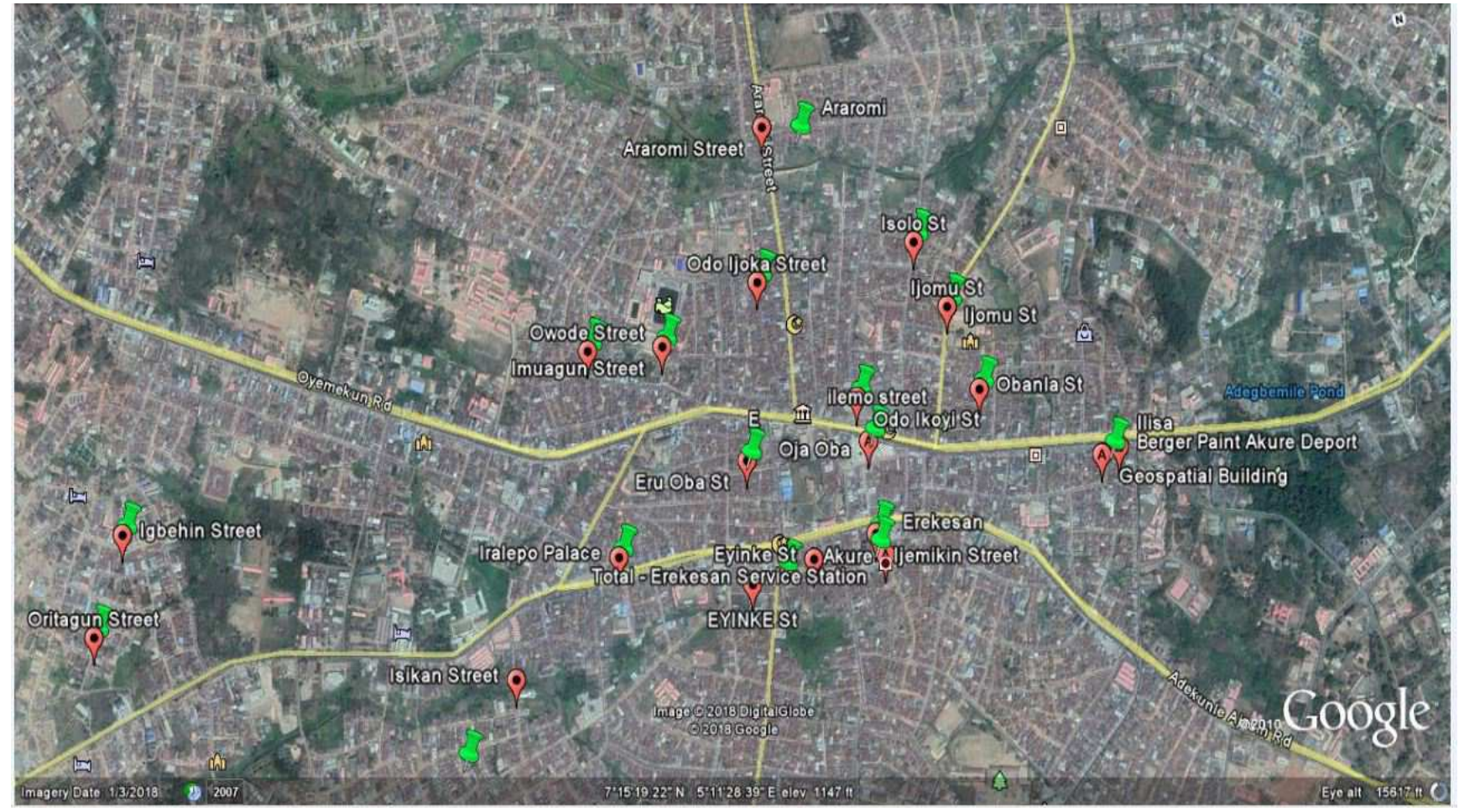

Figure 2. Google imagery of settlements in the core area of Akure town, Ondo state.

The survey carried out showed that, the study area was a high density area with $48.58 \%$ linear distribution pattern and $51.42 \%$ cluster distribution pattern in other parts of the study area. Table 4 shows that $38.13 \%$ and $43.3 \%$ of the sampled buildings were detached and semi- detached buildings respectively, $5.18 \%$ of the sampled buildings were block of flats while $13.42 \%$ were other types of buildings, mostly storey-buildings. This is a major characteristic of core area housing in relation to density, settlement pattern and type of buildings which showed the quality of housing development in the study area. $14.65 \%$ of the sampled buildings had less than $30 \%$ building coverage, $37.53 \%$ and $35.45 \%$ of the 
sampled buildings covered $30-40 \%$ and $41-50 \%$ land area respectively while $12.4 \%$ of the sampled buildings covered $51-60 \%$ of land area which implied that, the buildings were not up to building standards.

$89.46 \%$ of the sampled buildings in the study area were built over 10 years ago (table 4), 8.87\% had been in existence for 2-5 years while $1.67 \%$ had been in existence for $6-10$ years which showed that the study area is an old settlement due to their spatial structure. Major characteristics of housing stock in urban centers were associated with settlement patterns, building types, building coverage and age of buildings and most of these characteristics depict the deteriorating state of spatial structure associated with indigenous urban core such as Akure.

Table 4. Housing Characteristics in the core area of Akure, Ondo State.

\begin{tabular}{|c|c|c|c|c|c|c|c|c|}
\hline & Eruoba & Eyinke & Ijemikin & Ijomu & Ilemo & Isolo & Total & Percentage \\
\hline & Fr. \% & Fr. \% & Fr. \% & Fr. $\%$ & Fr. $\%$ & Fr. $\%$ & $\%$ & Fr. $\%$ \\
\hline Settlement & distribution & Pattern & & & & & & \\
\hline Linear & 3284.2 & 3775.5 & 1368.4 & 37 & 315 & 1241.4 & 291.5 & 10048.58 \\
\hline Cluster & 615.8 & 1224.5 & 631.6 & 4093 & 1785 & 1758.6 & 308.5 & 9851.42 \\
\hline \multicolumn{9}{|l|}{ Type of building } \\
\hline Detached & 1231.6 & 1428.6 & 1157.9 & 2251.2 & 525 & 1034.5 & 228.8 & 7438.13 \\
\hline Semi- detached & 2155.3 & 2142.9 & 421.1 & 1432.6 & 1470 & 1137.9 & 259.8 & 8543.3 \\
\hline Block of flats & - & 1122.4 & 15.3 & - & - & 13.4 & 31.1 & 145.18 \\
\hline Others & 513.2 & 36.1 & 315.8 & 716.3 & 15 & 724.1 & 80.5 & 2513.42 \\
\hline \multicolumn{9}{|c|}{ Coverage of building } \\
\hline less than $30 \%$ & 615.8 & 1224.5 & 210.5 & 1023.3 & - & 413.8 & 87.9 & 3414.65 \\
\hline $30 \%-40 \%$ & 2463.2 & 1836.7 & 736.8 & 1125.6 & 525 & 1137.9 & 225.2 & 7637.53 \\
\hline $41 \%-50 \%$ & 821.1 & 1530.6 & 947.4 & 1637.2 & 735 & 1241.4 & 212.7 & 6735.45 \\
\hline $51 \%-60 \%$ & - & 48.2 & 15.3 & 614 & 840 & 26.9 & 74.4 & 2112.4 \\
\hline \multicolumn{9}{|l|}{ Age of building } \\
\hline $2-5$ years & 513.2 & - & - & - & 840 & - & 53.2 & 138.87 \\
\hline $6-10$ years & - & - & - & - & 210 & - & 10 & 21.67 \\
\hline over 10 years & 3386.8 & 49100 & 19100 & 43100 & 1050 & 29100 & 536.8 & 18389.46 \\
\hline Total & 38100 & 49100 & 19100 & 43100 & 20100 & 29100 & 600 & 198100 \\
\hline
\end{tabular}

The condition of the sampled buildings through survey shows that $34.85 \%$ were in a fair condition and $48.25 \%$ were in a poor condition while $3.6 \%$ were in a good condition and $13.3 \%$ were in a very good condition. This implied that urban issues such as urban sprawl, slum area etc. was seen in the study area which is a major attribute of a core area settlement. $46.04 \%$ of the housing infrastructures in the study area were in a fair condition, $32.2 \%$ were in a very poor condition while $19.26 \%$ of the infrastructures were in good shape.

$82.95 \%$ of the sampled buildings used Zinc/ corrugated iron sheet as their roofing material, $9.12 \%$ and $7.93 \%$ used asbestos material and long span aluminum respectively as their roofing material. $46.85 \%$ and $53.15 \%$ used Mud block and cement block respectively as their walling materials while $91.82 \%$ of the sampled buildings used cement floor as their flooring material and $8.18 \%$ used tiles as their flooring material.

This implied that the existing condition of housing including housing facilities and infrastructures was poor in the study area due to age of buildings and poor building

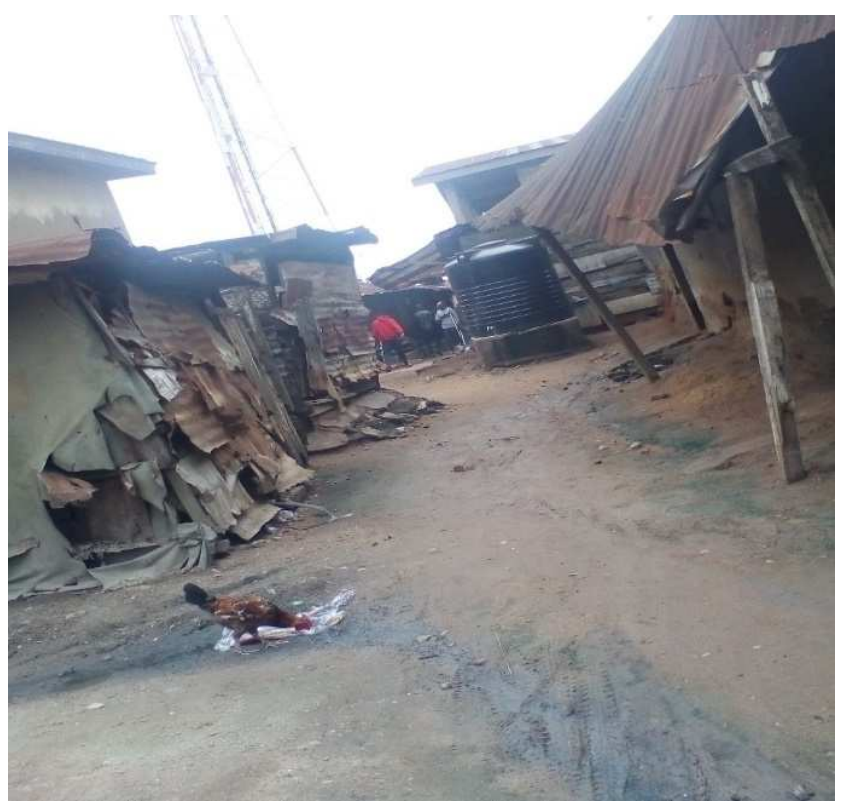
maintenance culture in the study area. 


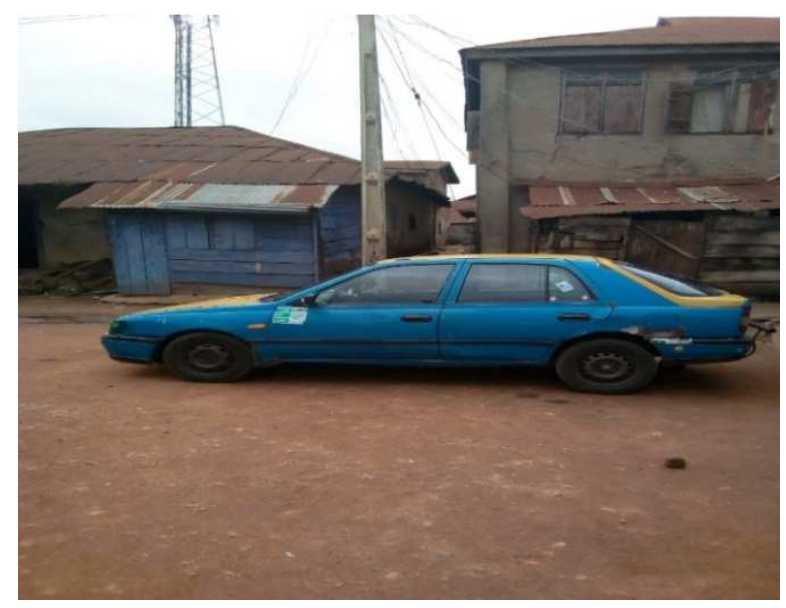

Figure 3. Condition of housing and infrastructure in Isolo, core area of Akure.

From the survey, $42.83 \%$ of the respondents requested for additional housing units while $57.17 \%$ agreed otherwise. This implied that, psychological housing problem of being deprived of good dwellings affected the resident of the area being a low income settlements with high number of those who did not need additional home due to financial incapability and lack of access to housing loans.

The survey also shows that $15.12 \%$ of the habitable rooms in the study had 1-2 persons per room, $62.12 \%$ had 3-4 persons per room, $18.1 \%$ had $5-6$ persons per room while $4.67 \%$ had above 6 persons per room. This is an indication overcrowding index and low number of housing facilities in the study area due to low housing quantity to support the density of the study area.

In Eruoba, Eyinke and Ijomu, inadequate finance and conflicts were the major difficulties faced in securing housing while issues such as insecurity and distance were the other problems identified. $42.25 \%$ of the respondents, stated that rate of housing development was very low in the study area, $29.38 \%$ had very low development, $3.83 \%$ were undecided about it, $20.8 \%$ had high rate of development while $3.75 \%$ had very high rate of housing development and seeing that there were little or no government interventions/programs towards housing developments, $51.85 \%$ of the respondents financed their housing developments through private source, $0.83 \%$ used mortgage, $39.83 \%$ used cooperative while $7.48 \%$ used other sources to finance their development such as family contributions, gifts etc.

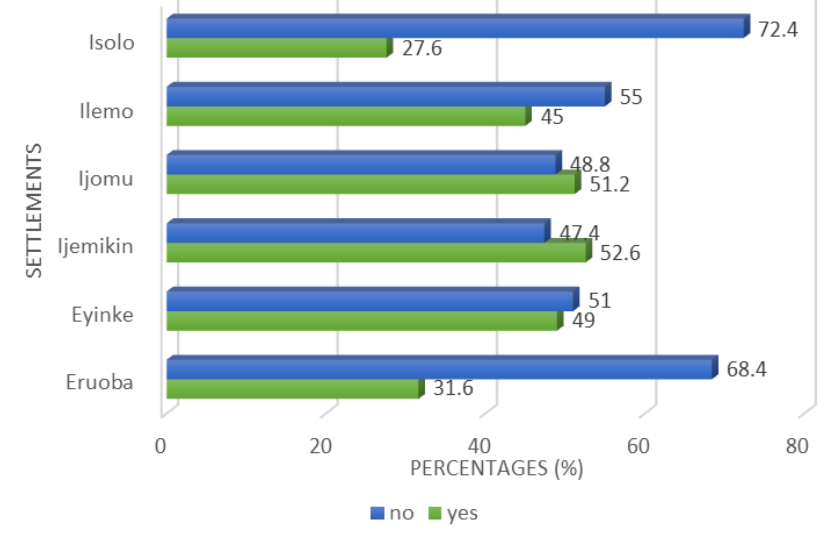

Figure 4. Need for additional housing units in the core area of Akure.

Using Mann-Whitney U-test to know the significance difference between the existing housing stock and current housing needs in the core area of Akure, Table 5 presents the result of hypothesis of the study stated in null form, that there no significant difference between housing stock and housing needs in the study area. Given the normal distribution (Zcal), which was -7.901 , the absolute value was, $|-7.901|=7.901$ and comparing with the Ztab which is 1.96 with $5 \%$ level of significance. Since Zcal $>$ Ztab, we accept the alternative hypothesis which showed that there is great quantitative housing need in the study area. However, the null hypothesis which states that there is no significant difference in housing stock and housing needs in the study area was rejected since the $\mathrm{p}$-value generated was less than 0.05 .

Table 5. Test statistics for significant difference between existing housing stock and current housing needs in the core area of Akure.

\begin{tabular}{llll}
\hline & Treatment & N & Mean Rank \\
\hline & housing stock & 114 & 147.47 \\
significant difference & housing needs & 114 & 81.53 \\
& Total & 228 & 9294.50 \\
\hline
\end{tabular}

Table 6. Mann-Whitney U-test.

\begin{tabular}{ll}
\hline & Significant difference \\
\hline Mann-Whitney U & 2739.500 \\
Wilcoxon W & 9294.500 \\
Z & -7.901 \\
Asymp. Sig. (2-tailed) & .000 \\
a. Grouping Variable: treatment & \\
\hline
\end{tabular}

The $\mathrm{p}$ values is 0.000 which is less than 0.05 , therefore, we reject the null hypothesis $\left(H_{o}\right)$ and accept the alternate hypothesis which state that, there is a significance difference between the existing housing stock and housing needs in the core area of Akure. There was high quantitative housing need in the core area of Akure in respect to the existing housing stock in the study area due to the increased population that could not match the existing housing stocks. In essence, high levels of illiterate, large numbers of household, changing of residential buildings to commercial were among the factors responsible for this. 


\section{Conclusion}

The study examines the quantitative analysis of housing needs in the core area of Akure, Ondo State, with a view to identify the quantity of housing stock in the study area, examine the socio-economic characteristics of housing dwellers in the study area, assess the existing condition of housing in the study area and investigate the current housing needs in the study area. The results of this study indicate housing affordability problems in the study area. It also revealed that the majority of householders in the city lack basic facilities that make housing conducive and by extension promote the development of the built environment; therefore there is need for significant recommendations in order to improve housing in the core area of Akure and urban centers as a whole.

\subsection{Adopt Housing Affordability Strategy to Improve Housing Stock}

[1] defined the term "affordable housing" as that which costs no more than 30 percent of the income of the occupant household. Since the concept is an essential component of sustainable development, housing affordability strategy should be adopted to increase housing stock because of its importance in securing some given standards of housing or different standards at a price or rent. This does not impose an unreasonable burden on household incomes and it will also ensure that the normal power for the development of individual housing as well as housing purchase is exercised.

\subsection{Urban Renewal}

There is need for upgrading programme through rehabilitation/renovation approach as well as provision of urban basic services. This simply involves rejuvenation of affected parts of the area by retaining some structures that are retainable; rehabilitate old buildings and structures, upgrading the roads that are not tarred and introduction of more roads with a view to open up the blighted areas. It also involves improving the existing infrastructures as well as providing new ones. These are improving the structural quality and aesthetic of the areas.

\subsection{Economic Revitalization}

Generation of employment opportunities, otherwise known, as economic revitalization is highly needed in the area. This will help to improve the level of capital base and potential for capital formation among the residents that will enhance their level of provision for basic household facilities and proper maintenance of buildings. This approach offers future proceed that can sustain any improvement effort that may be put in place to revive the area.

\subsection{Improvement on Housing Facilities and Infrastructures}

Since rental housing constitute the largest proportion of housing market in the city core, government should develop an effective and efficient rental housing market by involving in its direct participation through production of new units and housing facilities along with the environmental and infrastructural facilities. Government should also introduce social housing (local council housing) which is an umbrella term referring to rental housing which may be owned and managed by the state, for social gains or profit maximization or a combination of the two, usually with the aim of providing affordable housing. This will go a long way in reducing the current astronomical price. The quality of houses tends to reduce as the degree of density or level of crowdedness increases, therefore, the general lack of a sound maintenance culture among the residents should be addressed and basic requirements for livable environments should be provided.

\subsection{Governmental and Institutional Intervention to Cater for Housing Needs}

There is also a need for governmental and institutional intervention to cater for housing needs and general lack of infrastructures, such as roads, drains, sanitation waste disposal and recreational facilities. All state holders should collaborate towards enforceable standards for houses already built and future builds in order to guarantee the city sustainable development. Rapid urban development has brought dynamic changes to large and medium size cities in the developing countries. The decaying nature of the core areas in Nigerian cities and other developing countries over the last decades has also brought into focus the need for housing researchers and decision makers to develop a better understanding of the structure, operation and dynamics of urban centers. This study discussed the socio-economic characteristics, the housing conditions and the problems emanating from it and the housing needs in the core area of Akure. It notes the occurrence of rapid rate of urbanization occurring in the country, the consequences of which have been severely degraded urban environment. It reports the poor housing conditions in the core areas of Akure, the capital city of Ondo State, Nigeria and proffers recommendations to improve them and reduce the poverty level of the residents.

\section{Acknowledgements}

The author wants to acknowledge the contribution of his research students - Gbadebo Adejumoke and Ajuwon Adeola for their involvement during the field survey and data analysis. Also, the Federal University of Technology, Akure Nigeria for providing the research environment for the success of the research.

\section{References}

[1] Afolabi, A. (2008). Housing policy formulation in developing countries: Evidence of programme implementation from Akure, Ondo State, Nigeria. Housing Policy Formulation in Developing Countries, 23 (2), 125-134. 
[2] Agbola, T. (1998). The housing of Nigerians: A review of policy development and implementation, Research report, 14, Development Policy Centre. Ibadan.

[3] Arati, S., Macwan, J., \& Dhiraj, S. (2012,). Urbanization and its impact on housing. p. 1.

[4] Arayela, o. (2004). Towards a sustainable housing programme: the recurring problem of inadequate housing suppy and urban degradation environmental in Nigeria. Proceedings of XXXII World Congress on Housing at the International Conference on Sustainability of housing project (pp. 21-25). University of Trento, Italy, Trento: International Association of Science (IAHS).

[5] Bratt, R. (2002). Housing and family well-being. Housing Studies 17: 13-26.

[6] Briggs, X. (2003). Housing opportunity, desegregation strategy, and policy research. Journal of Policy Analysis and Management 22: 201-6.

[7] Burchell, Robert, Litosken. (1995). Influences on United States housing policy. Housing Policy Debate 6: 559-617.

[8] Coker, A., Awokola, O., Olomolaiye, P., \& Booth, C. (2008). Challenges of urban housing quality and its associations with neighborhoods environments: Insights and experiences of Ibadan City, Nigeria. Journal of Environmental Health Research, 7 (1), 21-30.

[9] Dunn, James R. (2000). Housing and health inequalities: Review and prospects for research. Housing Studies 15: 34166.

[10] Enisan, O. F. (2017). Effects of land prices on housing densities in residential estates of Akure, Nigeria. Ph.D Seminar presented at the Department of Urban and Regional Planning, Federal University of Technology, Akure. October, 2017.

[11] Federal Government of Nigeria, F. (2004). National housing policy for Nigeria. Abuja: Federal Ministry of Works and Housing.

[12] Galster, G. (2005). A review of existing research on the effects of federally assisted housing programs on neighboring residential property values. Chicago, IL: National Association of Realtors.

[13] Jargowsky. (2006). Concentration of poverty and metropolitan development. Paper read at Concentrated Poverty: What, Where and Why. Dallas, Texas.

[14] Katz, B. (2006). Racial division and concentrated poverty. Washington, DC: Brookings Institution.
[15] National Population Census. (2006). the priority tables generated from the 2006 population and housing census. Abuja: NPC.

[16] Nkwogu, u. (2001). Sustainable urban development policy issues in Nigeria. Architects and architecture in Nigeria: a tribute to Prof. E. A. Adeyemi, 117-208.

[17] Olanrewaju, D. (2001). Urban infrastructure a critique of urban renewal process. Ijora Badia: Habitat International 20.

[18] Olotuah, A. (1997). The house: accessibility and development - A critical evaluation of the Nigerian. In B. Amole (Ed.), Proceedings of the National Symposium (pp. 312-317). Ile Ife, Nigeria: Obafemi Awolowo University.

[19] Olotuah, A. (2002). An Appraisal of the Impact of Urban Services on Housing in Akure Metropolis. Journal of Science, Engineering and Technology, 4 (9), 4570-4582.

[20] Olotuah, A. (2005). Sustainable urban housing provision in Nigeria: A critical assessment of development option. Proceedings of the Africa Union of Architects Congress, (pp. 64-74). Abuja.

[21] Olotuah, A. (2015). Accessibility of low-income earners to public housing in Ado-Ekiti, Nigeria. Journal of Civil and Environmental Research, 7 (7), 1-5.

[22] Olotuah, A., \& Taiwo, A. (2015). Housing strategies and quality of housing in Nigeria: what lessons from Wales? Developing Country Studies, 5 (16), 1-3.

[23] Olotuah, A. O., Aiyetan, A. O. (2006). Sustainable low-cost housing provision in Nigeria: a bottom-up, participatory approach. Proceedings of 22nd Annual ARCOM Conference, 2, 633-639.

[24] Olujinmi, I. (2000). SINA Technical Workshop on Housing Co-operative, Nairobi. Nairobi.

[25] Rivkin, Steven G. (1994). Residential segregation and school integration. Sociology of Education 67: 279-92.

[26] Squires, Gregory, Kubrin. (2005). Privileged places: Race, uneven development and the geography of opportunity in urban America. Urban Studies 42: 47-68.

[27] United Nation Population Fund [UNPF] (2017). The power of 1.8 billion: adolescents, youth and the transformation of the future. State of World Population 2017 Report, United Nation Population Fund (UNPR). www.unfpa.org.

[28] UN-Habitat (2016). Urbanization and development: Emerging futures. World cities report, 2016. Kenya: United Nation Human Settlement Programmes. 